\title{
Development of Ligands for the Peripheral Benzodiazepine Receptor
}

\author{
Michelle L. James ${ }^{1}$, Silvia Selleri² and Michael Kassiou*,1,3 \\ ${ }^{1}$ Department of Pharmacology, University of Sydney, NSW 2006, Australia \\ ${ }^{2}$ Dipartimento di Scienze Farmaceutiche, Università di Firenze, Via G. Capponi 9, 50121 Firenze, Italy \\ ${ }^{3}$ Department of PET and Nuclear Medicine, Royal Prince Alfred Hospital, Missenden Road, Camperdown NSW \\ 2050, Australia
}

\begin{abstract}
The peripheral benzodiazepine receptor (PBR) initially characterised as a high affinity binding site for diazepam, is densely distributed in most peripheral organs whilst only moderately expressed in the healthy brain. The predominant cell type expressing the PBR at regions of central nervous system (CNS) pathology are activated microglial cells. Under neuroinflammatory conditions there is an over-expression of PBR binding sites indicating that measurements of PBR density can act as a useful index of brain disease activity. The PBR is now considered a significant therapeutic and diagnostic target which has provided the impetus for PBR ligand development. There are several classes of PBR ligands available including benzodiazepines (Ro54864), isoquinoline carboxamides (PK 11195), indoleacetamides (FGIN-1-27), phenoxyphenyl-acetamides (DAA1106) and pyrazolopyrimidines (DPA-713). Subsequent conformationally restrained isoquinoline and indoleacetamide analogues have been synthesised in an attempt to yield PBR ligands with superior affinity and brain kinetics. Even though the PBR has been linked to a number of biochemical processes, including cell proliferation, apoptosis, steroidogenesis, porphyrin transport and immunomodulation, its exact physiological role is yet to be deciphered. Selective PBR ligands with favourable in vivo binding properties and kinetics is required to gain a more complete understanding on the normal functioning of the PBR and the chemical pathways underlying several pathological conditions. Novel PBR ligands with unique binding properties and functional activity may also generate information on the localisation of the PBR and the possibility of PBR subtypes. This review highlights the main classes of PBR ligands to date. In addition the biological activity and therapeutic potential of certain PBR ligands is discussed.
\end{abstract}

\section{INTRODUCTION}

The peripheral benzodiazepine receptor $(\mathrm{PBR})$ is a complex and elusive molecular entity that has been the focus of much research ever since it was identified in peripheral tissue as an alternative binding site for the benzodiazepine, diazepam [1]. Initially the PBR was believed to be a subtype of the central benzodiazepine receptor (CBR) however it was later distinguished as a novel and discrete class of receptor due to its unique structure, cellular location and putative functional roles [2, 3].

The tryptophan rich, $18 \mathrm{kDa}$ protein known as the PBR, is highly hydrophobic and consists of 169 amino acids [4]. It is presently accepted that the PBR forms a trimeric complex with the $32 \mathrm{kDa}$ voltage-dependent anion channel (VDAC) and the $30 \mathrm{kDa}$ adenine nucleotide carrier (ANC) [5] to constitute the mitochondrial permeability transition pore (MPTP) (Fig. 1). Another protein coupled with this receptor is PBR associated protein-1 (PRAX-1) which is thought to aid in the modulation of PBR function via the recruitment of additional targets [6]. The precise composition of the MPTP is enigmatic with several other proteins implicated in its regulation.

The PBR has a ubiquitous distribution in most peripheral organs including the kidney and heart [7] whilst

*Address correspondence to this author at the Department of PET and Nuclear Medicine, Royal Prince Alfred Hospital, Missenden Road, Camperdown NSW 2050, Australia; Tel: (612) 95155150; E-mail: mkassiou@med.usyd.edu.au the highest concentrations are in the steroid producing tissues [8]. Later studies showed that the PBR is also minimally expressed in the normal brain [9]. Although the PBR has been localised in the mitochondria, and in particular the outer mitochondrial membrane [10], further studies indicated the presence of PBR in cellular structures that are completely devoid of mitochondria such as in mature human red blood cells. Consequently it can be concluded that PBRs are predominately mitochondrial even though other cellular regions of expression are possible [9].

There is a vast amount of evidence suggesting the involvement of PBRs in a number of biological processes however its exact physiological role remains ambiguous. The PBR is believed to be involved in modulating immune response [11], porphyrin transport and heme synthesis [12], regulation of cell proliferation [13], steroid biosynthesis [7, 14-16] and programmed cell death [17]. Of these, the most documented functional role of the PBR is its apparent association with steroidogenesis. Molecular modelling of mouse 18-kDa PBR protein was performed under the condition that the five transmembrane domains of the PBR were modelled as five $\alpha$-helices spanning the outer mitochondrial membrane. This model was evaluated as a cholesterol carrier and it was found that the PBR can house a cholesterol molecule and act as a channel [15]. These results together with in vitro functional assays indicate that the PBR plays a vital role in the transportation of cholesterol from the outer to inner mitochondrial membrane which is known to be the rate limiting step of steroid biosynthesis [18]. A number of PBR specific ligands, both endogenous 


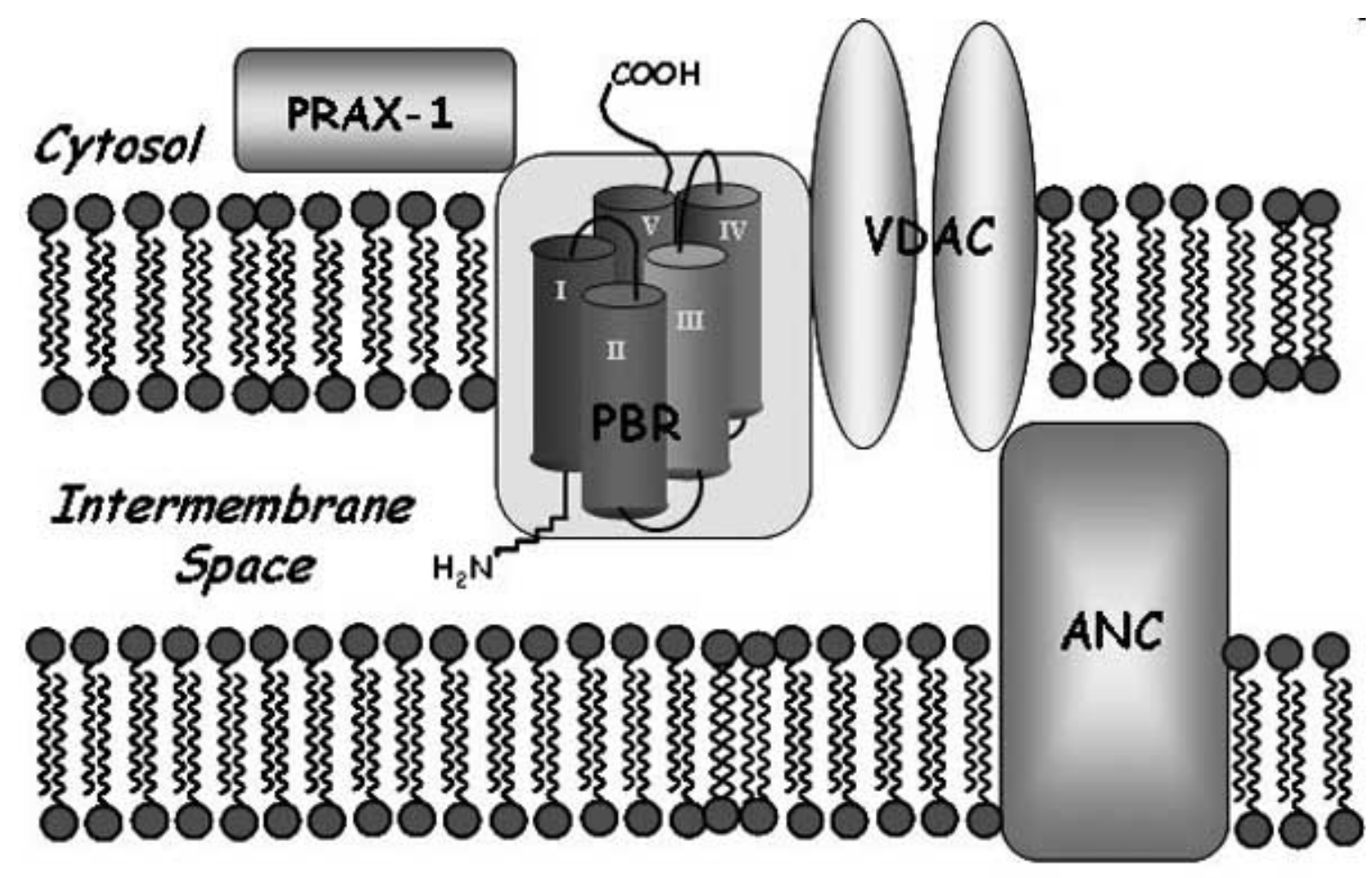

\section{Mitochondrial Matrix}

Fig. (1). Peripheral benzodiazepine receptor complex.

and exogenous, have been shown to promote the translocation of cholesterol to the inner mitochondrial membrane where it is metabolised into pregnenolone, the parent molecule of all mammalian steroids, by cytochrome P450 scc (side chain cleavage) [19]. PBR ligands can therefore increase the concentration of neurosteroids in the brain. These neurosteroids, including progesterone, dehydroepiandrosterone and their metabolites, positively modulate $\gamma$-aminobutyric acid (GABA) neurotransmission leading to nonsedative anxiolytic effects which are of therapeutic benefit in memory and stress related disorders [20]. Apart from the potential use of PBR ligands in anxiety related disorders, it has been postulated that they could be useful in treating both inflammatory conditions [21, 22] and cardiovascular diseases [23].

Although the PBR is only modestly expressed in normal brain parenchyma, in vivo studies in humans have demonstrated an over-expression of the PBR within a number of pathological disease states including malignant brain tumours [24] and a number of neurodegenerative and neuroinflammatory diseases [25]. The exact cellular source of this increased PBR density in the brain had been controversial for many years until a number of in vitro and in vivo studies using PK 11195, a specific PBR ligand, were performed. High resolution micro-autoradiography with $\left[{ }^{3} \mathrm{H}\right] \mathrm{PK} \quad 11195$, alongside immunohistochemistry, demonstrated that elevated PBR binding directly correlated with the appearance of activated microglia [26]. More recently, in vivo positron emission tomography (PET) imaging using $\left[{ }^{11} \mathrm{C}\right] \mathrm{PK} 11195$ in patients suffering from Alzheimer's disease (AD) and multiple sclerosis (MS) confirmed that the distribution of increased PBR binding corresponded with the histologically well documented activation of microglia $[27,28]$.

Microglia are the principal immune effecter cells of the central nervous system (CNS) [29]. These macrophage-like immune cells are assumed to derive from monocytic lineage [30] and their primary role lies in host defence and immune surveillance. They are highly sensitive to changes in their microenvironment and rapidly become activated in response to pathological events [31]. Microglia in their activated state express increased levels of major histocompatibility complex type II (MHCII) and secrete a host of neurotoxic factors such as tumour necrosis factor $\alpha$ (TNF $\alpha$ ), interferon $\gamma$ (IFN $\gamma$ ), interleukin-1 $\beta$ (IL-1 $\beta$ ) and reactive oxygen intermediates [32]. These factors often work in synergy to fuel inflammatory responses which can eventually lead to neurodegeneration [33]. While there is no doubt that activated microglia are intimately associated with the progression of neuroinflammation, their exact role in the cascade of immunological events is not entirely understood.

It is generally accepted that an increase in PBR density is a reliable marker of microglial activation and neuroinflammation [34] and can therefore be used as an index of active disease in the brain. For that reason the development of novel PBR ligands is important not only for therapeutic applications but they can also provide a means for assessing alterations in PBR density. PBR ligands can thus serve as tools for unravelling the complex cascade of biochemical events involved in the initial stages of several neuropathologic diseases. This could potentially lead to 
earlier detection of disease, monitoring of disease progression and even the design of more specific treatments.

Already several classes of PBR ligands have been reported. The benzodiazepines, diazepam and Ro 5-4864, were the principal class used in identifying the PBR as a distinct receptor from the CBR. Since then, a variety of structurally related classes have been developed including the benzothiazepines and the benzoxazepines. Another class of PBR ligands, structurally unrelated to the benzodiazepines, are the isoquinolines from which PK 11195 is currently the most widely use PBR ligand [34] and regarded as the gold standard. Numerous other classes have been developed, however most are riddled with factors which limit their use in characterising the PBR in vivo. Therefore a range of ligands with varying biological activity that possess suitable in vivo properties is required to better characterise the physiological and therapeutic roles of the receptor, its exact localisation and the anticipated existence of PBR subtypes. This paper will provide an overview of the currently available PBR ligands, their limitations and their usefulness as molecular probes for microglial activation.

\section{ENDOGENOUS LIGANDS}

Over the last few decades a number of putative endogenous ligands for the PBR have been proposed including anthralin, diazepam-binding inhibitor (DBI) and some key porphyrin molecules. Identifying and investigating endogenous PBR ligands is an important step in characterising this receptor and in elucidating its in vivo physiological function.

A $16 \mathrm{kDa}$ protein was isolated from rat antral stomach and found to specifically inhibit the binding of $\left[{ }^{3} \mathrm{H}\right] \mathrm{Ro} 5$ 4864 to PBRs. Interestingly this protein, termed anthralin, was also shown to inhibit the well known calcium antagonist, $\left[{ }^{3} \mathrm{H}\right]$ nitrendipine, from binding to the dihydropyridine $\mathrm{Ca}^{2+}$ channel. In addition it was demonstrated that $\mathrm{Ca}^{2+}$ ions increase the intrinsic activity of anthralin in a dose-dependent manner. It has since been postulated that anthralin could be an endogenous ligand interacting with both PBRs and dihydropyridine sites in a dual-like fashion. Both pharmacological and electrophysiological data indicate functional coupling between these two receptor systems [9].

An $11 \mathrm{kDa}$ neuropeptide, endowed with multiple biological actions, was isolated and purified to homogeneity from rat brain by monitoring its ability to displace $\left[{ }^{3} \mathrm{H}\right]$ diazepam from high affinity receptor sites localised in crude synaptic membranes [35]. This brain polypeptide, named diazepam binding inhibitor (DBI), was shown to be highly expressed in steroidogenic cells and was thus suggested to play a vital role in stimulating the initial stages of steroid biosynthesis. Examination of radiolabelled DBI in the presence of mitochondria from R2C rat Leydig tumour cells provided evidence that DBI bound directly to the 18$\mathrm{kDa}$ PBR protein [36]. Once bound to the PBR, DBI promotes the translocation of cholesterol from the outer to the inner mitochondrial membrane and hence leads to neurosteroid synthesis. Both DBI and its processing product DBI 17-50 (TTN) are capable of stimulating steroid production at concentrations of $10^{-8} \mathrm{M}$ [14]. Overall DBI is classified as a competitive inhibitor of $\left[{ }^{3} \mathrm{H}\right]$ diazepam and the CBR specific ligand $\left[{ }^{3} \mathrm{H}\right]$ flumazenil. DBI displays the same low (mM) affinity for the CBR as it does for the PBR and has been shown to be a negative modulator of the GABA activated $\mathrm{Cl}^{-}$channels present in $\mathrm{GABA}_{\mathrm{A}}$ receptors [37]. At present DBI is the most logical candidate for an endogenous PBR ligand.

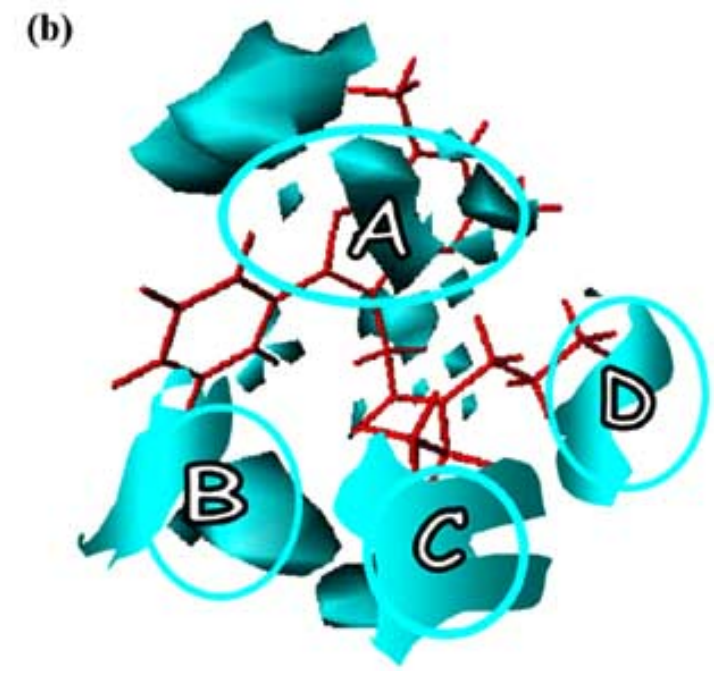

Fig. (2). (a) Proposed PBR pharmacophore model for pyrazolopyrimidine ligands according to the alignment of Alpidem proposed by Anzini, M.; et al. J. Med. Chem., 1996, 39, 4275-4284

$\mathrm{FRA}=$ freely rotating aromatic ring region, $\delta 1=$ electron-rich zone, $\mathrm{PAR}=$ planar aromatic region, $\mathrm{LA}=$ lipophilic area.

(b). Representation of the lipophilic areas (A, B, C, D) thought to be important for PBR affinity of pyrazolopyrimidine ligands. This representation was constructed by using the GRID/Golpe model proposed by Selleri, S.; et al. Bioorg. Med. Chem 2005, 13, 48214834. It is clear that there is a high degree of correlation between the interaction areas shown in Fig. 2a and Fig. 2b (A: PAR); (B: FRA); (C,D: LA). 
Some of the key biological porphyrins, heme and protoporphyrin IX, have been reported as highly selective endogenous ligands for the PBR with $K_{\mathrm{i}}$ values of $41 \mathrm{nM}$ and $15 \mathrm{nM}$ respectively. Both are significantly less active at the CBR with $K_{\mathrm{i}}$ values $>10,000 \mathrm{nM}$ [38]. This high nanomolar selectivity and definite correlation between PBR rich tissues and porphyrin levels imply a biochemical communication between porphyrin molecules and PBRs [9].

\section{SYNTHETIC LIGANDS}

There are numerous synthetic compounds that are known to bind the PBR with varying selectivity and affinity. Over the last few decades various PBR pharmacophores have been postulated by different groups [39-41] alongside extensive structure activity relationship (SAR) studies. A hydrogenbond donor group ( $\delta 1$ : usually a carbonyl oxygen), two lipophilic regions (PAR and FRA) and another lipophilic region involved in modulating receptor binding (LA) are the general features of the most recently proposed PBR pharmacophore and are said to be necessary for a ligand to interact with the PBR. This pharmacophore is illustrated in Fig. 2a using pyrazolopyrimidines as an example. Fig. 2b depicts the molecular interaction fields important for PBR binding as constructed via the use of the GRID/Golpe model [42].

\subsection{Benzodiazepines}

The classical benzodiazepine, diazepam (Fig. 3), has long been used as an anxiolytic and also as an effective anticonvulsant. Its ability to enhance the affinity of GABA for the $\mathrm{GABA}_{\mathrm{A}}$ receptor by binding to the modulatory site on this receptor has been well characterised [43]. It was not until a series of arduous binding studies were performed using $\left[{ }^{3} \mathrm{H}\right]$ diazepam that an alternative binding site for diazepam was identified [1]. The results from these binding studies indicated strong, specific binding of $\left[{ }^{3} \mathrm{H}\right]$ diazepam $(\sim 3 \mathrm{nM})$ to a single, saturable binding site located on rat brain membranes. However, $\left[{ }^{3} \mathrm{H}\right]$ diazepam was also shown to bind mitochondrial fractions from rat kidney, liver and lung with high potency. Results from the same study indicated that Ro 5-4864, a clinically inactive benzodiazepine (Fig. 3), was unable to displace $\left[{ }^{3} \mathrm{H}\right]$ diazepam from central binding sites whereas it could potently displace it from kidney mitochondria.<smiles>CN1C(=O)CN=C(c2ccccc2)c2cc(Cl)ccc21</smiles>

Diazepam

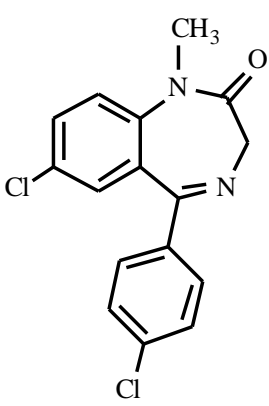

Ro 5-4864
Fig. (3). Benzodiazepine PBR ligands.

In contrast, clonazepam effectively inhibited binding of $\left[{ }^{3} \mathrm{H}\right]$ diazepam to brain sites yet it only displayed mild inhibitory actions on kidney binding. These curious observations suggested that diazepam was binding two distinct sites, the CBR and the "peripheral-type" binding site, with nanomolar affinity. Since Ro 5-4864 appeared selective for the peripheral binding site it was utilised in a number of successive studies, including a landmark study by Marangos and colleagues in 1982, which aided in the characterisation of this site. It was found that GABA didn't effect $\left[{ }^{3} \mathrm{H}\right]$ Ro 5-4864 binding but influenced the binding of $\left[{ }^{3} \mathrm{H}\right]$ diazepam thus proving the lack of coupling to the GABA system unlike that observed with the CBR. Interestingly, these "peripheral-type" sites were also shown to be present in the brain. In fact, the normal brain contains four times more central sites compared to peripheral type binding sites [44]. Taken together, these results confirm that this "peripheral-type" binding site, now known as the PBR, is a distinct molecular entity from the CBR, with its own unique subcellular location and structure.

Although Ro 5-4864 is a potent, selective ligand that has been used in numerous PBR studies it has been shown to be species dependent [45], providing markedly different results between rats and humans. This ultimately limits its usefulness as a tool for studying the PBR.

\subsection{Isoquinoline Carboxamides}

The isoquinoline carboxamide, (1-[2-chlorophenyl]- $N$ methyl- $N$-[1-methyl-propyl]-3-isoquinoline carboxamide) PK 11195 (Fig. 4), was the first non-benzodiazepine type compound identified to bind the PBR with high potency (Table 1). In vitro and in vivo studies in both rats and mice demonstrated the superior binding affinity of PK 11195 compared to Ro 5-4864 [7]. A binding study using membranes from rat kidney tissue and $\left[{ }^{3} \mathrm{H}\right] \mathrm{PK} 11195$ demonstrated the affinity of PK 11195 and Ro 5-4684 as Ki<smiles>CCC(C)N(C)C(=O)c1cc2ccccc2c(-c2ccccc2Cl)n1</smiles>

PK 11195<smiles>[X]c1ccccc1-c1c(C)c(C(=O)N([R])[R])nc2ccccc12</smiles>

VC
Fig. (4). Isoquinoline carboxamide PBR ligands.

Table 1. Structures and Affinities of Isoquinoline Carboxamides. IC $_{50}$ Values were Determined Using rat Cortex Homogenate and $\left[{ }^{3} \mathrm{H}\right] \mathrm{PK} 11195$

\begin{tabular}{|c|c|c|c|c|c|}
\hline Ligand & $\mathbf{X}$ & $\mathbf{R}_{\mathbf{1}}$ & $\mathbf{R}_{\mathbf{2}}$ & $\mathbf{I C}_{\mathbf{5 0}}(\mathbf{n M})$ & $\mathbf{R e f}$ \\
\hline \hline $\mathrm{VC} 195$ & $\mathrm{H}$ & $\mathrm{CH}_{2} \mathrm{C}_{6} \mathrm{H}_{5}$ & $\mathrm{CH}_{3}$ & 2.1 & {$[48]$} \\
\hline $\mathrm{VC} 193 \mathrm{M}$ & $\mathrm{H}$ & $s-\mathrm{Bu}$ & $\mathrm{CH}_{3}$ & 2.1 & {$[48]$} \\
\hline $\mathrm{VC} 198 \mathrm{M}$ & $\mathrm{F}$ & $s-\mathrm{Bu}$ & $\mathrm{CH}_{3}$ & 2.9 & {$[48]$} \\
\hline $\mathrm{PK} 11195$ & - & - & - & 2.2 & {$[48]$} \\
\hline
\end{tabular}


$=9.3 \mathrm{nM}$ and 23.0 respectively [19]. The high selectivity of PK 11195 was evidenced by its lack of activity on central benzodiazepine, catecholaminergic, GABAergic and opiate receptors [47].

Although both Ro 5-4864 and PK 11195 bind the PBR in a saturable and reversible manner with nanomolar affinity, they differ substantially in their kinetics and pharmacological profile. One significant difference stems from the fact that PBR isoquinoline binding sites are more abundant in the normal human brain than PBRbenzodiazepine sites [49]. In fact, the maximal binding site densities for PK 11195 are approximately three fold higher compared to Ro 5-4864 in brain regions such as the cortex, cerebellum and pons [49].

An interesting array of functional activity has been reported for PK 11195 over the past few decades. Early thermodynamic analysis indicated that the binding of $\left[{ }^{3} \mathrm{H}\right] \mathrm{PK} 11195$ is entropy driven compared to the enthalpy driven binding of $\left[{ }^{3} \mathrm{H}\right]$ Ro 5-4864 [46]. Steroidogenic assay results using C6 glioma rat cells showed that PK 11195 (40 $\mu \mathrm{M})$ stimulated the formation of pregnenolone significantly [19] however at the same concentration PK 11195 suppressed the increase in pregnenolone accumulation caused by other specific PBR ligands such as FGIN-1-27 [50].

A study by Versijpt et al. 2003 demonstrated that PK 11195 reduced the amount of inflammatory mediators, such as TNF $\alpha$ and nitric oxide (NO), released by activated microglia cells [51]. This indicates that PBR ligands may be able to alter biochemical processes in the brain and hence may have therapeutic benefits in certain neurological disorders. The synthesis of selective ligands for the PBR is therefore invaluable not only in characterising the receptor but also since the PBR could itself be a worthwhile target for therapeutic intervention.

PK 11195 has been used in countless activated microglia studies and has provided a number of novel insights on the cellular pathology involved in certain disease states including MS [52] and AD [53]. Consequently, PK 11195 has been tagged the gold standard of PBR ligands. Despite the frequent use of PK 11195, it has been shown to have a low brain permeability and highly variable kinetic behaviour. For these reasons, the sensitivity of PK 11195 in assessing and studying the PBR is significantly limited [54]. These poor characteristics have been attributed to the high lipophilicity and low bioavailability of PK 11195 ( $88 \%$ bound to plasma protein) [34]. Although these issues are still under debate, binding studies revealed that $\alpha 1$-acid glycoprotein (AGP) is the primary plasma protein to which PK 11195 binds [54]. Since plasma AGP levels vary between individuals, especially in individuals with underlying pathological diseases, the level of free PK 11195 in the plasma can be unpredictable and thus may contribute to the inconsistent kinetic behaviour of this ligand.

In an attempt to develop PBR ligands with more suitable kinetic profiles, a number of conformationally restrained isoquinoline-carboxamide derivatives of PK 11195 were synthesised [48]. The general structure of these VC compounds and their affinity compared to PK 11195 are shown in Fig. 4 and Table 1. Preliminary studies indicated that these compounds, VC195, VC193M and VC198M, had higher levels of brain permeability and specific binding [55].
However, once assessed in vivo, these derivatives did not display improved affinity or kinetics compared to PK 11195 [34].

\subsection{Benzothiazepines}

A novel class of ligands referred to as the 6-(pmethoxyphenyl)pyrrolo[2,1- $d][1,5]$-benzothiazepines, were identified in 1990 and their affinity for GABA and benzodiazepine receptor subtypes were evaluated [56]. Several of these ligands including THIA-66 and THIA-67 (Fig. 5, Table 2), displayed nanomolar affinity and notable selectivity for PBR binding sites (Table 2) however they were shown to be less potent than PK 11195. Initial studies identified the 6,7-double bond and the 6-aryl substitution moieties as important structural properties for PBR activity [57].

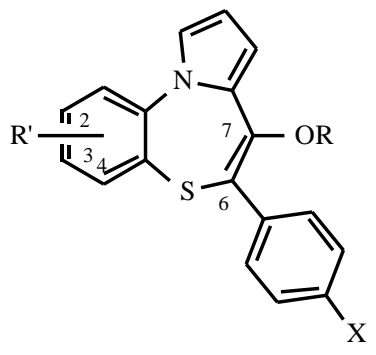

Fig. (5). General structure of benzothiazepine-type PBR ligands.

Table 2. Structures and Affinities of Key Benzothiazepines. IC $_{50}$ Values were Determined Using rat Cortex Homogenate and $\left[{ }^{3} \mathrm{H}\right] \mathrm{PK} 11195$

\begin{tabular}{|c|c|c|c|c|c|}
\hline Ligand & $\mathbf{R}$ & $\mathbf{R}$ & $\mathbf{X}$ & $\mathbf{I C}_{\mathbf{5 0}}$ (nM) & Ref \\
\hline \hline THIA-66 & $\mathrm{COCH}_{3}$ & $\mathrm{H}$ & $\mathrm{OCH}_{3}$ & 34 & {$[57]$} \\
\hline THIA-67 & $\mathrm{SO}_{2} \mathrm{CH}_{3}$ & $\mathrm{H}$ & $\mathrm{OCH}_{3}$ & 95 & {$[57]$} \\
\hline THIA-68 & ${\mathrm{CON}\left(\mathrm{CH}_{3}\right)_{2}}_{1}$ & $4-\mathrm{Cl}$ & $\mathrm{H}$ & 4.0 & {$[58]$} \\
\hline THIA-4i & $\mathrm{CON}\left(\mathrm{Et}_{2}\right)_{2}$ & $4-\mathrm{Cl}$ & $\mathrm{H}$ & 2.0 & {$[40]$} \\
\hline PK 11195 & - & - & - & 2.0 & {$[40]$} \\
\hline
\end{tabular}

Following these encouraging preliminary results a threedimensional quantitative structure-activity relationship (3DQSAR) model utilising the comparative molecular field analysis (COMFA) method was developed [58]. This model predicted the $\mathrm{IC}_{50}$ values of a test set of seven pyrrolobenzothiazepines with significant accuracy as verified by the experimentally determined $\mathrm{IC}_{50}$ values. One compound from this test set, referred to as THIA-68 (Fig. 5, Table 2), consisted of $4-\mathrm{Cl}$ and $7-\mathrm{CON}\left(\mathrm{CH}_{3}\right)_{2}$ substitution which are features typically found independently on most of the potent ligands in this class. Hence this proved the additive effects of substituents on overall ligand affinity.

More recently, a group of optimised ligands based on the same benzothiazepine structure have been synthesised [40] SAR studies on these derivatives provided evidence that substitution of the pyrrole moiety for a pyrrolidinone ring resulted in a compound with no activity (i.e. it was not active at the highest concentration tested, $10^{-5} \mathrm{M}$ ). Similarly, when the $[1,5]$ thiazepine ring was transformed to 
a thiazine or thiazocine ring, the overall affinity of the ligand was significantly reduced $\left(\mathrm{IC}_{50}=1340 \mathrm{nM}\right)$ [40]. These studies also indicated the importance of other structural components for optimal activity for PBR binding, including a diethyl carbamoyloxy group at the $\mathrm{C}-7$ position and a chlorine atom at the 4-position. To date, THIA-4i has been reported as the most potent PBR ligand from this class with an affinity comparable to that of the gold standard PBR ligand PK $11195\left(\mathrm{IC}_{50}=2.0 \mathrm{nM}\right.$ ) (Fig. 5, Table 2).

Although these ligands might be useful probes for in vitro studies, further evaluation is required to elucidate their in vivo pharmacological profile.

\subsection{Benzoxazepines}

The benzoxazepines were synthesised based on a pyrrolobenzoxazepine skeleton. The ligands from this class were evaluated in binding studies where their ability to displace $\left[{ }^{3} \mathrm{H}\right]$ PK 11195 from the receptor site was measured. A number of these compounds displayed $K_{\mathrm{i}}$ values in the subnanomolar range. OXA-17f and OXA-17j (Fig. 6, Table 3) were reported as the most potent PBR ligands from this series with $K_{\mathrm{i}}$ values of 0.26 and $0.36 \mathrm{nM}$ respectively compared to $K_{\mathrm{i}}$ value of $0.78 \mathrm{nM}$ for PK 11195 in the same assay [39]. These benzoxazepines were shown to be inactive on $\mathrm{GABA}_{\mathrm{A}}$ and $\mathrm{CBRs}$ and were thus found to be highly selective for the PBR.

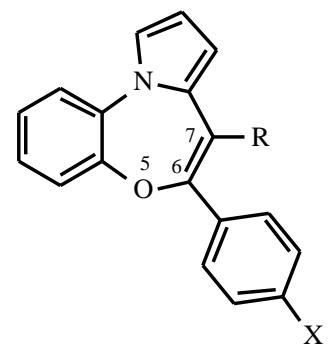

Fig. (6). General structure of benzoxazepine-type PBR ligands.

Table 3. Structure and Binding Affinities of Key Benzoxazepines. $K_{i}$ Values were Determined Using Rat Cortex Homogenate and $\left[{ }^{3} \mathrm{H}\right] \mathrm{PK} 11195$ (C6 Glioma Cells were Used for NF 213 and NF 182).

\begin{tabular}{|c|c|c|c|c|}
\hline Ligand & $\mathbf{R}$ & $\mathbf{X}$ & $\boldsymbol{K}_{\mathbf{i}}(\mathbf{n M})$ & $\mathbf{R e f}$ \\
\hline \hline OXA-17f & $\mathrm{OCON}(\mathrm{Et})_{2}$ & $\mathrm{H}$ & 0.26 & {$[39]$} \\
\hline OXA-17j & $\mathrm{OCON}(\mathrm{Et})_{2}$ & $\mathrm{CH}_{3}$ & 0.36 & {$[39]$} \\
\hline OXA-11a & $\mathrm{OCO}(\mathrm{NEt})_{2}$ & $\mathrm{H}$ & 0.11 & {$[59]$} \\
\hline NF 213 & $\left.\mathrm{OCON}_{(\mathrm{CH}}\right)_{2}$ & $\mathrm{CH}_{3}$ & 2.1 & {$[60]$} \\
\hline NF 182 & $\mathrm{OCON}_{\left(\mathrm{CH}_{3}\right)_{2}}$ & $\mathrm{H}$ & 2.8 & {$[60]$} \\
\hline PK 11195 & - & - & 0.78 & {$[39]$} \\
\hline
\end{tabular}

All of these benzodiazepine-like compounds were shown to stimulate neurosteroid production with comparable potency to PK 11195 and Ro 5-4864 in mouse Y-1 adrenocortical cell line. In a later study by Zisterer et al. 1998, a few of the lead benzoxazepines, also referred to as NF compounds, were used to decipher the role of the PBR in cell proliferation [60]. The effect of PBR ligands on cell growth was investigated by subjecting two individual cell lines, rat C6 glioma cells and human astrocytoma 1321N1, to a variety of PBR ligands including PK 11195, Ro5-4864 and the benzoxazepines; NF 182, NF 213 (Fig. 6, Table 3) and NF 262 (equivalent to OXA-17j). Interestingly the NF compounds, although originally designed as benzodiazepine analogues, showed no species dependence in binding the PBR. Unlike Ro 5-4864, the NF compounds bound both rodent and human cell lines with similar potency [60]. All of the tested PBR ligands produced analogous antiproliferative effects and it was found that these effects were not proportional to the potency of the ligand. Furthermore, the antiproliferative effects observed seemed to be unrelated to binding of these ligands to the PBR as the concentration required to produce the effect was 1000-fold greater than that needed to saturate the PBR sites.

Several compounds from this series were also utilised as molecular instruments to probe the spatial dimensions of the postulated binding pockets in the PBR cleft. This helped characterise the PBR binding site, mainly the LA and $\delta_{1}$ regions, whilst simultaneously identifying key ligand structural features required for high affinity interaction. In general, ligands comprised of a phenyl ring at C-6 and symmetric dimethyl/diethylcarbamoyl moieties at $\mathrm{C}-7$ were the most active. Later in 2002, Campiani and co-workers extended this series with the hope of further characterising the effects of different alkylcarbamoyl groups at the 7position which was thought to interact with the PAR lipophilic region of the PBR site [59]. After varying the carbamoyl nitrogen substituents it was found that replacement of a methyl by an ethyl group led to a 20-fold improvement in affinity and that monosubstitution at this C-7 position was more favourable than the previously investigated symmetrical disubstitution. The most potent PBR ligand from this class known at present is OXA-11a with a $K_{\mathrm{i}}$ value of $0.11 \mathrm{nM}$ (Fig. 6, Table 3). The ethyl group was identified as optimum in this position for PBR binding as it enabled a stronger interaction with the relatively large lipophilic binding pocket PAR.

All of the ligands from this novel series of benzoxazepines displayed sub-nanomolar affinity for rat brain and mitochondrial rat testis PBR. The biological efficacy of these new ligands was demonstrated by their distinct ability to enhance the endogenous rate of progesterone synthesis in MA10 Leydig cells at micromolar concentrations. Although these compounds have higher affinity than PK 11195 in both rodent and human cell lines, in vivo pharmacokinetic and pharmacodynamic data is still lacking.

\subsection{Indoleacetamide Derivatives}

Almost 15 years ago, when the PBR was referred to as the mitochondrial DBI receptor (MDR), a class of potent (nM) ligands for the PBR were developed by the use of the Fischer indole synthesis and named 2 aryl-3-indoleacetamides (FGIN-1) [50], [61]. These derivatives were found to enhance steroidogenesis and to be highly selective for the PBR as they lacked binding to glycine, glutamate, serotonin and GABA related receptors. The lead compound from this 


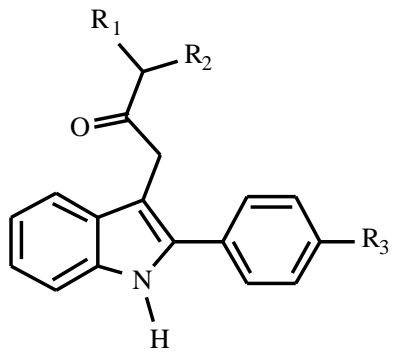

2- Arylindol-3-acetamides

FGIN-1-27: $\mathrm{R}_{1}=\mathrm{R}_{2}=n-\mathrm{C}_{6} \mathrm{H}_{13} ; \mathrm{R}_{3}=\mathrm{F}$

Fig. (7). Indoleacetamide PBR ligands.

class is known as $N, N$-di-n-hexyl 2-(4-fluorophenyl)indole3-acetamide (FGIN-1-27) (Fig. 7).

FGIN-1-27 has a high affinity $\left(K_{\mathrm{i}}=5.0 \mathrm{nM}\right.$, displacement study using $\left[{ }^{3} \mathrm{H}\right] \mathrm{PK} 11195$ [61]) and is able to penetrate the blood brain barrier. The fact that FGIN-1-27 can enter the brain explains how it is able to inhibit the onset of isoniazid-induced convulsions. This anticonvulsant effect is inhibited by PK 11195. FGIN-1-27 has also been shown to induce sedation and ataxia at micromolar intravenous doses. It was hypothesised that the pharmacological actions of this compound are most likely due to its indirect action on $\mathrm{GABA}_{\mathrm{A}}$ receptors via the stimulation of neurosteroid production [62].

Binding studies with primary glial cell cultures from newborn rat cerebella revealed a few structural features of FGIN-1 derivatives essential for high affinity PBR binding. $N, N$-Dialkylation of the amide is essential and the length of the alkyl group is an important consideration when synthesising a high affinity PBR compound from this class. FGIN-1 ligands with $N, N$-dihexyl groups have an affinity 20 times that of ligands with $N, N$-dimethyl substitution. However, alkyl groups with more than six carbon atoms displayed a decreased binding affinity [61]. Furthermore, $N, N$-dihexyl derivatives with halogen substitution on one or both of the aryl rings further enhanced their affinity [50].

Following the successful development of the FGIN-1 derivatives as high affinity PBR ligands, a series of conformationally restrained analogues of these compounds were synthesised comprising the $N, N$-dialkyl-2-phenylindol3-ylglyoxylamide derivatives (indolylglyoxylamides) [20]. SAR studies were performed and the results were considered in light of the most recently reported pharmacophore. Again

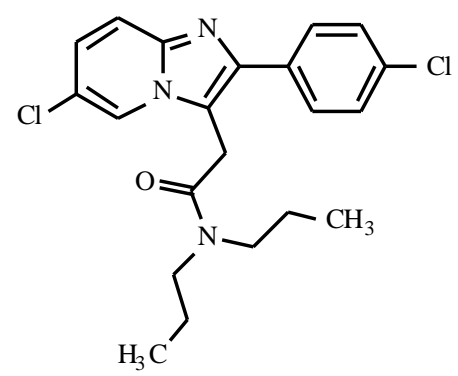

Alpidem

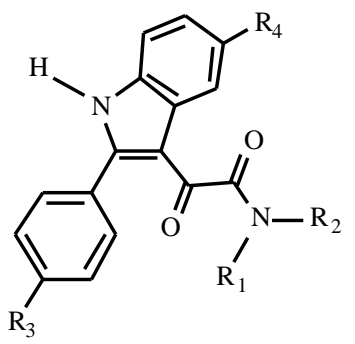

$N, N$-Dialkyl-2-phenylin dolyl glyoxylamides IND-18: $\mathrm{R}_{1}=\mathrm{R}_{2}=n-\mathrm{C}_{6} \mathrm{H}_{13} ; \mathrm{R}_{3}=\mathrm{F} ; \mathrm{R}_{4}=\mathrm{H}$

it was found that dialkylation of the amide is an essential component for high PBR affinity as it allows both the LA and PAR regions to be occupied. Most of these new ligands displayed high affinity for the PBR with $K_{\mathrm{i}}$ values in the nanomolar and subnanomolar range. The ligand with the greatest potency from this class was IND-18 (Fig. 6) with a $K_{\mathrm{i}}$ of $0.37 \mathrm{nM}$, compared to $9.3 \mathrm{nM}$ for PK 11195 in the same binding assay [20]. Twenty of the most potent ligands from this class were evaluated for their ability to stimulate pregnenolone synthesis in rat C6 glioma cells. It was generally found that, 4'-substituted derivatives increased pregnenolone concentration effectively when compared to PK 11195 and Ro 5-4864, whereas unsubstituted analogues didn't produce any marked effects [20].

Another high affinity PBR ligand belonging to this class of compounds, 7-chloro- $N, N$-5-trimethyl-4-oxo-3-phenyl3,5-dihydro-4H-pyrid-azino[4,5- $b$ ]indole-1-acetamide (SSR 180575), has been shown to promote neuronal survival and repair. SSR180575 displays nanomolar affinity, four times greater than that of Ro-5 4864, for both the rat and human PBR. This ligand was evaluated in rat models of both peripheral and central neurodegeneration in vivo and the observed neuroprotective effects appear to require only partial occupancy (50 to $70 \%$ ) of the PBR. Moreover, SSR180575 increased pregnenolone accumulation in the brain implying that the therapeutic effects may be mediated through its ability to stimulate steroidogenesis [63].

Both FGIN-1-27 and SSR180575 have been shown to cross the $\mathrm{BBB}$ however they require further in vivo evaluation in order to gain information about their kinetics and binding properties. All of the ligands from this class are more lipophilic than PK 11195 and therefore to what extent this will affect their in vivo kinetics needs to be addressed.

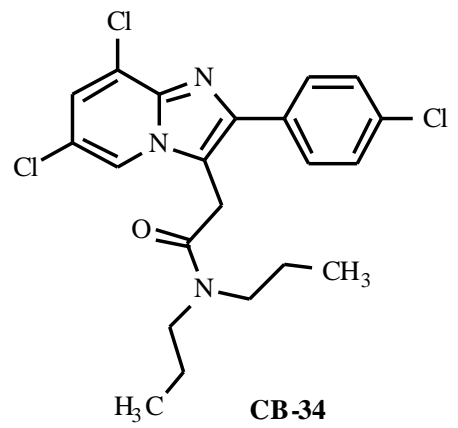

Fig. (8). Imidazopyridine PBR ligands. 
Overall these compounds appear to be good therapeutic candidates however more data is required in determining their value.

\subsection{Imidazopyridines}

Alpidem (Fig. 8) is the primary member of the imidazopyridines and is known to bind both the PBR and CBR with nanomolar affinity $\left(K_{\mathrm{i}}=0.5-7 \mathrm{nM}\right.$ and $1-28 \mathrm{nM}$ respectively) [19]. Whilst alpidem has the ability to stimulate steroidogenesis and is recognised as a clinically active anxiolytic [64] its non selective nature limits its potential in elucidating the physiological and pharmacological roles of the PBR.

In 1997 Trapani and colleagues performed a number of SAR studies on alpidem in attempting to develop a novel range of imidazopyridine derivatives with improved selectivity for the PBR compared to the CBR [65]. As part of these studies, the substituents and acetamide moiety of alpidem were varied whilst maintaining the 2phenylimidazo[1,2-a]-pyridine heterocyclic ring system. This led to the formation of a series of selective PBR ligands known as 2-phenyl-imidazo[1,2-a]-pyridines. Based on results from radioligand binding assays, it was shown that disubstitution at 6- and 8- positions on the pyridine moiety with dichloro, dibromo, 6- $\mathrm{CF}_{3} / 8$-chloro, 6-bromo/8$\mathrm{CH}_{3}$ or $6-\mathrm{CH}_{3} / 8-\mathrm{Br}$ substituents was a core feature in promoting selectivity for the PBR. Further SAR and structure-selectivity relationship (SSR) research helped explore the effects of modifying the alkyl groups attached to the amide functionality and resulted in the synthesis of an extended series of 2-phenyl-imidazo[1,2-a]-pyridine derivatives [66]. In 1999, three lead compounds from this series, $N, N$-di- $n$-propyl-[2-(4-chlorophenyl)-6,8-dichloroimidazo[1,2-a]-pyridin-3-yl)]acetamide (CB 34), N,N-di- $n$ propyl-[2-phenyl-6,8-dichloroimidazo[1,2-a]-pyridin-3-yl)]acetamide (CB 50) and $N, N$-di-n-propyl-[2-phenyl-6-bromo8-methyl-imidazo[1,2-a]-pyridin-3-yl)]acetamide (CB 54), were investigated for their agonistic effect on brain and plasma neurosteroid concentrations in normal and adrenalectomized-orchiectomized (ADX-ORX) rats [67]. CB34, CB 50 and CB 54 all competed with [ $\left.{ }^{3} \mathrm{H}\right] \mathrm{PK} 11195$ for binding to membrane preparations of rat cerebral cortex and displayed $\mathrm{IC}_{50}$ values of $1.03,3.04$ and $1.54 \mathrm{nM}$ respectively ( $\mathrm{PK} 11195, \mathrm{IC}_{50}=1.43$ in the same assay) [67]. All three ligands were shown to stimulate steroidogenesis in rats which was indicated by elevated cortical concentrations of pregnenolone, progesterone, allopregnanolone and allotetrahydro-deoxycorticosterone (THDOC). Of these three ligands CB 34 (Fig. 7) appeared the most promising due to its high affinity, selectivity and ability to stimulate steroidogenesis both peripherally and centrally with a greater potency than PK 11195.

$N, N$-Di- $n$-butyl-[2-(4-chlorophenyl)imidazo[1,2-a]pyridin3 -yl)]acetamide, although displaying high PBR affinity (5$10 \mathrm{nM}$ ), was the only reported 2-phenyl-imidazo[1,2-a]pyridine that failed to have any effect on neuroactive steroid concentration in cerebral cortex and is thus considered to be an antagonist [66]. These results proved that there was no direct association between affinity and selectivity for the PBR and functional steroidogenic activity. The use of both agonists and antagonists is essential in identifying and understanding different functional states of the PBR. As a more diverse range of specific and selective PBR ligands become available more knowledge can be gained on the structural differences between agonist and antagonist binding sites. To date only a limited number of imidazopyridines have been evaluated in preliminary in vivo studies. A more exhaustive and systematic evaluation is required in order to better understand their pharmacological profile.

\subsection{Phenoxyphenyl-Acetamide Derivatives}

Two phenoxyphenyl-acetamide derivatives, $\mathrm{N}$-(4chloro-2-phenoxyphenyl)- $N$-(2-isopropoxybenzyl)acetamide (DAA1097) and $N$-(2,5-dimethoxybenzyl)- $N$-(5-fluoro-2phenoxyphenyl)acetamide (DAA1106) (Fig. 9), were derived by opening the diazepine ring of Ro5-4864. They have since been reported as specific ligands for the PBR [68] and display potent anxiolytic effects in laboratory animals [69].

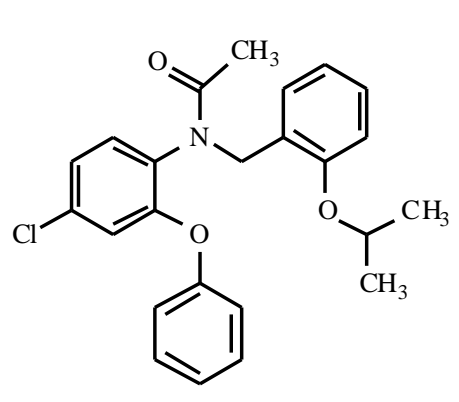

DAA1097<smiles>COc1ccc(OC)c(CN(C(C)=O)c2cc(F)ccc2Oc2ccccc2)c1</smiles>

DAA1106
Fig. (9). Phenoxyphenyl-acetamide PBR ligands.

These ligands are extremely selective as they have high affinity for the PBR and only negligible affinity for 58 other receptors including a number of neurotransmitter-related, ion channels, transporters and second messengers [69]. Both DAA1097 and DAA1106 have been shown to inhibit $\left[{ }^{3} \mathrm{H}\right] \mathrm{PK} 11195$ binding to mitochondrial preparations of rat whole brain with $\mathrm{IC}_{50}$ values of 0.92 and $0.28 \mathrm{nM}$ respectively ( $\mathrm{PK} 11195, \mathrm{IC}_{50}=1.12 \mathrm{nM}$ in the same assay). Likewise, in the same preparation, these ligands inhibited the binding of the benzodiazepine Ro 5-4864 with $\mathrm{IC}_{50}$ values of 0.64 and $0.21 \mathrm{nM}\left(\mathrm{PK} 11195, \mathrm{IC}_{50}=1.63\right.$ in the same assay) [69]. In a separate study DAA1106 was evaluated in both monkey brain and mitochondrial fractions of rat brain. The results indicated that this ligand was not species dependent as it bound with high affinity in both monkey and rat brain having $K_{\mathrm{i}}$ values of 0.188 and 0.043 nM respectively [70].

In 1999, Chaki and colleagues demonstrated that $\left[{ }^{3} \mathrm{H}\right]$ DAA1106 binding to the mitochondrial fraction of rat brain was saturable and that the dissociation constant $(\mathrm{Kd})$ determined from scatchard plot analysis was $0.12 \mathrm{nM}$ and indicated a single class of binding sites. Autoradiographic and biochemical studies revealed that the highest density binding of $\left[{ }^{3} \mathrm{H}\right] \mathrm{DAA} 1106$ in the brain was in the olfactory bulb, followed by the cerebellum and cerebral cortex [68].

Even though these phenoxyphenyl-acetamide derivatives have a similar structure and are potent anxiolytics they have opposite effects on steroidogenesis. In a study performed by Culty and colleagues in 2001 the effects of both DAA1097 
and DAA1106 on steroidogenic response of MA-10 Leydig tumour cells, C6-2B glioma cell and rat brain mitochondria was evaluated [71]. It was shown that DAA1097 was capable of stimulating a significant increase in progesterone synthesis in all three preparations similarly to that described for PK 11195 and Ro5-4864. In contrast, DAA1106 had no effect on steroidogenesis and in fact partially inhibited the binding of endogenous PBR ligands. It was thus concluded that DAA1097 appears to be an agonist and that DAA1106 may act as a competitive antagonist [71].

It has been postulated that DAA1097 and DAA1106 share common binding sites on the PBR with PK 11195. However they also appear to contain motifs that do not interact efficiently with PK 11195 suggesting their interaction with additional sites on the PBR [71]. This, along with the high affinity, selectivity and potential therapeutic role suggests that they represent useful tools for elucidating the exact biochemical role of the PBR.

\subsection{Pyrazolopyrimidines}

The pyrazolopyrimidines are bioisteres of the imidazopyridine derivatives and hence are structurally related to alpidem. Comprehensive SAR studies on the imidazo $[1,2-a]$ pyridine nucleus of alpidem were conducted to evaluate the influence of certain substitutions and modifications on selectivity toward the PBR. The 5- and 7positions were examined and the results from these studies led to the synthesis of the pyrazolopyrimidine compounds, displaying superior affinity and selectivity for the PBR when compared to both alpidem and PK 11195 [19]. Binding assays, using $\left[{ }^{3} \mathrm{H}\right] \mathrm{PK} 11195$ as the radioligand and membranes from rat kidney tissue as receptor source, showed that a subset of ligands from this pyrazolopyrimidine series displayed high binding affinity $\left(K_{\mathrm{i}}\right)$ for the PBR ranging from 0.8-6.1 nM. Some of these compounds were shown to stimulate steroid biosynthesis in C6 glioma rat cells with a few capable of increasing pregnenolone synthesis with similar potency to Ro 5-4864 and PK 11195 (namely PYRA-3j and PYRA-3q shown in Fig. 10, Table 4).

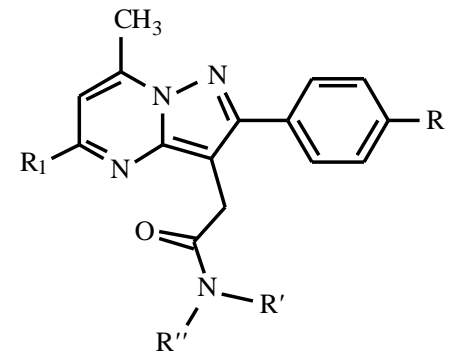

Fig. (10). General structure of pyrazolopyrimidine-type PBR ligand.

One potent ligand from this class, $N, N$-diethyl-2-[2-(4methoxyphenyl)-5,7-dimethyl-pyrazolo[1,5- $a$ ]pyrimidin-3yl]-acetamide (DPA-713) (Fig. 10, Table 4), exhibited no effect on steroidogenesis thus proving once again that there is no relationship between intrinsic activity and PBR affinity [19]. Overall it was found that the substitution at 5and 7- positions as well as having a 2-aryl substituent appeared to be the key factors promoting the PBR selectivity and the different functional activity of the pyrazolopyrimidines ligands in the steroidogenesis assay.
Table 4. Structure and Binding Affinities of Key Pyrazolopyrimidines. $K_{\mathrm{i}}$ Values were Determined Using Membranes from Rat Kidney Tissue and $\left[{ }^{3} \mathrm{H}\right]$ PK 11195

\begin{tabular}{|c|c|c|c|c|c|c|}
\hline Ligand & $\mathbf{R}$ & $\mathbf{R}_{\mathbf{1}}$ & $\mathbf{R}^{\prime}$ & $\mathbf{R}^{\prime \prime}$ & $\boldsymbol{K}_{\mathbf{i}}(\mathbf{n M})$ & Ref \\
\hline \hline DPA-713 & $\mathrm{OCH}_{3}$ & $\mathrm{CH}_{3}$ & $\mathrm{Et}$ & $\mathrm{Et}$ & 4.7 & {$[19]$} \\
\hline PYRA-3j & $\mathrm{Cl}$ & $\mathrm{CH}_{3}$ & $\mathrm{Et}$ & $\mathrm{Et}$ & 2.4 & {$[19]$} \\
\hline PYRA-3q & $\mathrm{CH}_{3}$ & $\mathrm{CF}_{3}$ & $\mathrm{Et}$ & $\mathrm{Et}$ & 1.0 & {$[19]$} \\
\hline PYRA-4d & $\mathrm{H}$ & $\mathrm{CH}_{3}$ & n-But & $n$-But & 4.5 & {$[42]$} \\
\hline PYRA-4j & $\mathrm{H}$ & $\mathrm{CH}_{3}$ & $\mathrm{Et}$ & $\mathrm{Ph}$ & 0.8 & {$[42]$} \\
\hline PK 11195 & - & - & - & - & 9.3 & {$[19]$} \\
\hline
\end{tabular}

Recently, further research has been conducted focusing on the 3-position in an attempt to determine the importance of the amide moiety and key structural features regarding the number and length of alkyl substituents on the amide nitrogen [42]. A 3D-QSAR model using GRID/Golpe procedure was implemented to assess the outcome of the substitution on the acetamide chain. This led to the generation of new pyrazolopyrimidines namely 2-phenyl-5,7dimethylpyrazolo[1,5-a]pyrimidin-3-yl acetamides. This newly synthesised group of ligands contained some promising compounds endowed with high specificity and selectivity for the PBR. Some of these displayed agonistic properties with greater potency than PK 11195, namely PYRA-4d and in particular PYRA-4j (Fig. 10, Table 4), whilst others showed clear antagonistic attributes. The GRID/Golpe model provided useful insights on the necessary features required for stereoselectivity at the PBR binding site and supported the concept of an asymmetric site containing two individual cavities [42].

\subsection{Vinca Alkaloids}

Vinpocetine (ethyl apovincaminate) (Fig. 11) was identified in the late 1960's and following its introduction to the market in 1978 (Cavinton ${ }^{\circledR}$, Gedeon Richter, Budapest, Hungary) it has been used in the prevention and treatment of various cerebrovascular diseases, including patients with acute and chronic stroke [72].

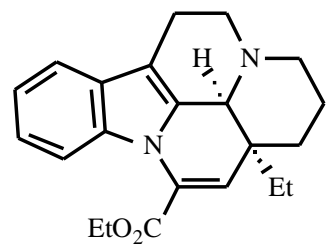

Vinpocetine

Fig. (11). Vinca alkaloid PBR ligand.

Lörincz and colleagues were the first to synthesise ethyl apovincaminate from the vinca minor alkaloid, vincamine [73]. Although vinpocetine has been shown to be a potent inhibitor of voltage dependent $\mathrm{Na}^{+}$channels [74] and $\mathrm{Ca}^{2+} /$ calmoduline-dependent phosphodiesterase type 1 (PDE-1 isoenzyme) [75, 76], the exact mechanism behind its well established neuroprotective properties remains unclear. In vitro binding studies have demonstrated that vinpocetine 
interacts with an extensive array of molecular targets Vinpocetine binds the PBR in rat heart with moderate affinity $\left(\mathrm{IC}_{50}=0.2 \mu \mathrm{M}\right)$ however it may not be an ideal tool for studying the PBR since it binds numerous other brain sites with similar affinity, including certain adrenergic receptor subtypes $\left(\alpha_{2 \mathrm{~B}} \mathrm{IC}_{50}=0.9 \mu \mathrm{M}, \alpha_{2 \mathrm{~A}} \mathrm{IC}_{50}=1.9\right.$ $\mu \mathrm{M}), \mathrm{Na}^{+}$channels (site $2 \mathrm{IC}_{50}=1.9 \mu \mathrm{M}$ ) and $\mathrm{Ca}^{2+}$ channels (L-type, benzothiazepin $\mathrm{IC}_{50}=2.1 \mu \mathrm{M}$, phenylakylamine $\mathrm{IC}_{50}=4.1 \mu \mathrm{M}$ ) [77].

\section{CONCLUSION}

PK 11195 has been used extensively in characterising the PBR in both normal and pathological states. It has not only provided useful information on the molecular identity of the PBR but has also showed promise as a potential therapeutic due to its anti-inflammatory action and its ability to increase the amount of neurosteroids in the CNS. However, the use of PK 11195 is severely limited by its far from ideal in vivo properties including its high lipophilicity and non specific binding.

Benzodiazepines that bind the PBR are interesting and may represent a class of PBR ligand with a slightly different binding pattern (site) compared to PK 11195. However they do show species dependence which ultimately limits their usefulness because extrapolating information from laboratory animals to humans is made difficult. Minimal information is known about the benzothiazepines and the benzoxazepines. These ligands have not been evaluated in vivo, their ability to penetrate the $\mathrm{BBB}$ has not been determined, their therapeutic value is unknown and they have not been radiolabelled for use in functional imaging. All of these areas need to be addressed before their importance as PBR probes can be established.

The non-selective nature of the vinca alkaloid vinpocetine is a limiting feature that has capped its potential as a tool for investigating the PBR. In contrast, there are a number of promising ligands from the indolacetamide, imidazopyridine, phenoxyphenyl-acetamide and pyrazolopyrimidine classes which could prospectively act as significant leads in understanding the molecular basis of the PBR.

Ligands from each of these four classes have demonstrated BBB penetration and highly potent, specific binding in vivo. There has been at least one ligand from each of the imidazopyridine, phenoxyphenyl-acetamide and pyrazolopyrimidine classes that has been labelled for in vivo imaging of the PBR. These ligands show promise as tools that may supersede PK 11195 however they first need to be completely evaluated in humans and their therapeutic efficacy needs to be assessed.

In summary, the PBR is an important molecular and therapeutic target with an enigmatic physiology. A diverse range of PBR ligands have been identified, however very little is still known about the fundamental characteristics of the receptor. The development of highly specific PBR ligands with favourable in vivo properties and differing functional activity, will further aid in the elucidation of biochemical role of the PBR and explore the possibility of PBR subtypes.

\section{REFERENCES}

[1] Braestrup, C.; Squires, R. Proc. Natl. Acad. Sci. USA, 1977, 74, 3805-3809.

[2] Casellas, P.; Galiegue, S.; Basile, A. S. Neurochem. Int., 2002, 40, 475-486.

[3] Kassiou, M.; Meikle, S. R.; Banati, R. B. Brain Res. Rev., 2005, 48, 207-210.

[4] Beurdeley-Thomas, A.; Miccoli, L.; Oudard, S.; Dutrillaux, B.; Poupon, M. F. J. Neuro-Oncol., 2000, 46, 45-56.

[5] McEnery, M. W.; Snowman, A. M.; Trifiletti, R. R.; Snyder, S. H. Proc. Natl. Acad. Sci. USA, 1992, 89, 3170-4.

[6] Galiegue, S.; Jbilo, O.; Combes, T.; Bribes, E.; Carayon, P.; Fur, G. L.; Casellas, P. J. Biol. Chem., 1999, 274, 2938-2952.

[7] Gavish, M.; Katz, Y.; Bar-Ami, S.; Weizman, R. J. Neurochem., 1992, 58, 1589-1601.

[8] Verma, A.; Snyder, S. H. Annu. Rev. Pharmacol. Toxicol., 1989, 29, 307-22

[9] Gavish, M.; Bachman, I.; Shoukrun, R.; Katz, Y.; Veenman, L.; Weisinger, G.; Weizman, A. Pharmacol. Rev., 1999, 51, 629-650.

[10] Anholt, R. R.; Pedersen, P. L.; De Souza, E. B.; Snyder, S. H. J. Biol. Chem., 1986, 261, 576-83, 1986 Jan 15.

[11] Zavala, F. Pharmacol. Ther., 1997, 75, 199-216.

[12] Taketani, S.; Kohno, H.; Furukawa, T.; Tokunaga, R. J. Biochem., 1995, 117, 875-80.

[13] Alho, H.; Varga, V.; Krueger, K. E. Cell Growth Different., 1994, $5,1005-14$

[14] Costa, E.; Auta, J.; Guidotti, A.; Korneyev, A.; Romeo, E. J. Steroid Biochem. Mol. Biol., 1994, 49, 385-9.

[15] Papadopoulos, V.; Amri, H.; Boujrad, N.; Cascio, C.; Culty, M.; Garnier, M.; Hardwick, M.; Li, H.; Vidic, B.; Brown, A. S.; Reversa, J. L.; Bernassau, J. M.; Drieu, K. Steroids, 1997, 62, 21 28.

[16] Krueger, K. E.; Papadopoulos, V. Annu. Rev. Pharmacol. Toxicol., 1992, 32, 211-37.

[17] Chelli, B.; Lena, A.; Vanacore, R.; Da Pozzo, E.; Costa, B.; Rossi, L.; Salvetti, A.; Scatena, F.; Ceruti, S.; Abbracchio, M. P.; Gremigni, V.; Martini, C. Biochem. Pharmacol., 2004, 68, 125134.

[18] Papadopoulos, V. Annales Pharmaceutiques Francaises, 2003, 61, 30-50.

[19] Selleri, S.; Bruni, F.; Costagli, C.; Costanzo, A.; Guerrini, G.; Ciciani, G.; Costa, B.; Martini, C. Bioorg. Med. Chem., 2001, 9, 2661-2671.

[20] Primofiore, G.; Da Settimo, F.; Taliani, S.; Simorini, F.; Patrizi, M P.; Novellino, E.; Greco, G.; Abignente, E.; Costa, B.; Chelli, B.; Martini, C. J. Med. Chem., 2004, 47, 1852-5.

[21] Bribes, E.; Bourrie, B.; Casellas, P. Immunol. Lett., 2003, 88, 241 247.

[22] Farges, R. C.; Torres, S. R.; Ferrara, P.; Ribeiro-do-Valle, R. M. Life Sci., 2004, 74, 1387-1395.

[23] Veenman, L.; Gavish, M. Pharmacol. Therap., 2006, In Press.

[24] Cornu, P.; Benavides, J.; Scatton, B.; Hauw, J. J.; Philippon, J. Acta Neurochirurgica, 1992, 119, 146-52.

[25] Wilms, H.; Claasen, J.; Rohl, C.; Sievers, J.; Deuschl, G.; Lucius, R. Neurobiol. Dis., 2003, 14, 417-24.

[26] Myers, R.; Manjil, L. G.; Cullen, B. M.; Price, G. W.; Frackowiak, R. S.; Cremer, J. E. J. Cereb. Blood Flow Metab., 1991, 11, 314 22.

[27] Banati, R. B.; Myers, R.; Kreutzberg, G. J. Neurocytol., 1997, 26, 77-82.

[28] Banati, R. B. Glia, 2002, 40, 206-17.

[29] Gonzalez-Scarano, F.; Baltuch, G. Ann. Rev. Neurosci., 1999, 22, 219-40

[30] Farber, K.; Kettenmann, H. Brain Res. Rev., 2005, 48, 133-43.

[31] Ladeby, R.; Wirenfeldt, M.; Garcia-Ovejero, D.; Fenger, C.; Dissing-Olesen, L.; Dalmau, I.; Finsen, B. Brain Res. Rev., 2005, 48, 196-206.

[32] Banati, R. B.; Gehrmann, J.; Schubert, P.; Kreutzberg, G. W. GLIA, 1993, 7, 111-8.

[33] Kreutzberg, G. W. TINS., 1996, 19, 312-8.

[34] Belloli, S.; Moresco, R.; Matarrese, M.; Biella, G.; Sanvito, F.; Simonelli, P.; Turolla, E.; Oliveri, S.; Cappelli, A.; Vomero, S.; Galli-Kienle, M.; Fazio, F. Neurochem. Int., 2004, 44, 433-440.

[35] Guidotti, A.; Corda, M. G.; Costa, E. Adv. Biochem. Psychopharmacol., 1983, 38, 95-103. 
[36] Garnier, M.; Boujrad, N.; Ogwuegbu, S. O.; Hudson, J. R., Jr.; Papadopoulos, V. J. Biol. Chem., 1994, 269, 22105-12.

[37] Bormann, J.; Ferrero, P.; Guidotti, A.; Costa, E. Regulat. Pept.Suppl., 1985, 4, 33-8.

[38] Verma, A.; Nye, J. S.; Snyder, S. H. Proc. Natl. Acad. Sci. USA, 1987, 84, 2256-60.

[39] Campiani, G.; Nacci, V.; Fiorini, I.; De Filippis, M. P.; Garofalo, A.; Ciani, S. M.; Greco, G.; Novellino, E.; Williams, D. C.; Zisterer, D. M.; Woods, M. J.; Mihai, C.; Manzoni, C.; Mennini, T. J. Med. Chem., 1996, 39, 3435-50.

[40] Campiani, G.; Nacci, V.; Fiorini, I.; De Filippis, M. P.; Garofalo, A.; Ciani, S. M.; Greco, G.; Novellino, E.; Manzoni, C.; Mennini, T. Eur. J. Med. Chem., 1997, 32, 241-251.

[41] Cinone, N.; Holtje, H.-D.; Carotti, A. J. Comput. Aided Mol. Des., 2000, $14,753-768$.

[42] Selleri, S.; Gratteri, P.; Costagli, C.; Bonaccini, C.; Costanzo, A.; Melani, F.; Guerrini, G.; Ciciani, G.; Costa, B.; Spinetti, F.; Martini, C.; Bruni, F. Bioorg. Med. Chem., 2005, 13, 4821-4834.

[43] Leonard, B. E. J. Psychosomatic Res., 1994, 38, 69-87.

[44] Marangos, P. J.; Patel, J.; Boulenger, J. P.; Clark-Rosenberg, R. Mol. Pharmacol., 1982, 22, 26-32.

[45] Farges, R.; Joseph-Liauzun, E.; Shire, D.; Caput, D.; Le Fur, G.; Ferrara, P. Mol. Pharmacol., 1994, 46, 1160-1167.

[46] Le Fur, G.; Vaucher, N.; Perrier, M. L.; Flamier, A.; Benavides, J.; Renault, C.; Dubroeucq, M. C.; Gueremy, C.; Uzan, A. Life Sci., 1983, 33, 449-57.

[47] Le Fur, G.; Perrier, M. L.; Vaucher, N.; Imbault, F.; Flamier, A.; Benavides, J.; Uzan, A.; Renault, C.; Dubroeucq, M. C.; Gueremy, C. Life Sci., 1983, 32, 1839-47.

[48] Cappelli, A.; Anzini, M.; Vomero, S.; Benedetti, P. G. D.; Menziani, M. C.; Giorgi, G.; Manzoni, C. J. Med. Chem., 1997, 40, 2910-2921.

[49] Raghavendra Rao, V.; Butterworth, R. Eur. J. Pharmacol., 1997, 340, 89-99.

[50] Kozikowski, A. P.; Ma, D.; Brewer, J.; Sun, S.; Costa, E.; Romeo, E.; Guidotti, A. J. Med. Chem., 1993, 36, 2908-20.

[51] Versijpt, J. J.; Dumont, F.; Van Laere, K. J.; Decoo, D.; Santens, P.; Audenaert, K.; Achten, E.; Slegers, G.; Dierckx, R. A.; Korf, J. Eur. Neurol., 2003, 50, 39-47.

[52] Banati, R. B.; Newcombe, J.; Gunn, R.; Cagnin, A.; Turkheimer, F.; Heppner, F.; Price, G.; Wegner, F.; Giovannoni, G.; Miller, D.; Perkin, G.; Smith, T.; Hewson, A.; Bydder, G.; Kreutzberg, G.; Jones, T.; Cuzner, M.; Myers, R. Brain, 2000, 123, 2321-2337.

[53] Cagnin, A.; Brooks, D.; Kennedy, A.; Gunn, R.; Myers, R.; Turkheimer, F.; Jones, T.; Banati, R. B. Lancet, 2001, 358, 461467.

[54] Lockhart, A.; Davis, B.; Matthews, J. C.; Rahmoune, H.; Hong, G.; Gee, A.; Earnshaw, D.; Brown, J. Nucl. Med. Biol., 2003, 30, 199 206.

[55] Matarrese, M.; Moresco, R. M.; Cappelli, A.; Anzini, M.; Vomero, S.; Simonelli, P.; Verza, E.; Magni, F.; Sudati, F.; Soloviev, D.; Todde, S.; Carpinelli, A.; Kienle, M. G.; Fazio, F. J. Med. Chem., 2001, 44, 579-85.

[56] Nacci, V.; Fiorini, I.; Garofalo, A.; Cagnotto, A. Farmaco, 1990, $45,545-557$.
[57] Fiorini, I.; Nacci, V.; Ciani, S. M.; Garofalo, A.; Campiani, G.; Savini, L.; Novellino, E.; Greco, G.; Bernasconi, P.; Mennini, T. J. Med. Chem., 1994, 37, 1427-38.

[58] Greco, G.; Novellino, E.; Fiorini, I.; Nacci, V.; Campiani, G.; Ciani, S. M.; Garofalo, A.; Bernasconi, P.; Mennini, T. J. Med. Chem., 1994, 37, 4100-8.

[59] Campiani, G.; Ramunno, A.; Fiorini, I.; Nacci, V.; Morelli, E.; Novellino, E.; Goegan, M.; Mennini, T.; Sullivan, S.; Zisterer, D. M.; Williams, C. D. J. Med. Chem., 2002, 45, 4276-81,

[60] Zisterer, D. M.; Hance, N.; Campiani, G.; Garofalo, A.; Nacci, V.; Williams, D. C. Biochem. Pharmacol., 1998, 55, 397-403.

[61] Romeo, E.; Auta, J.; Kozikowski, A. P.; Ma, D.; Papadopoulos, V.; Puia, G.; Costa, E.; Guidotti, A. J. Pharmacol. Exp. Ther., 1992, 262, 971-8.

[62] Romeo, E.; Cavallaro, S.; Korneyev, A.; Kozikowski, A. P.; Ma, D.; Polo, A.; Costa, E.; Guidotti, A. J. Pharmacol. Exp. Ther. 1993, 267, 462-71.

[63] Ferzaz, B.; Brault, E.; Bourliaud, G.; Robert, J.-P.; Poughon, G.; Claustre, Y.; Marguet, F.; Liere, P.; Schumacher, M.; Nowicki, J.P.; Fournier, J.; Marabout, B.; Sevrin, M.; George, P.; Soubrie, P.; Benavides, J.; Scatton, B. J. Pharmacol. Exp. Ther., 2002, 301, 1067-1078.

[64] Sanger, D. J.; Zivkovic, B. Psychopharmacology, 1994, 115, 395 403.

[65] Trapani, G.; Franco, M.; Ricciardi, L.; Latrofa, A.; Genchi, G.; Sanna, E.; Tuveri, F.; Cagetti, E.; Biggio, G.; Liso, G. J. Med. Chem., 1997, 40, 3109-18.

[66] Trapani, G.; Franco, M.; Latrofa, A.; Ricciardi, L.; Carotti, A.; Serra, M.; Sanna, E.; Biggio, G.; Liso, G. J. Med. Chem., 1999, 42, 3934-3941.

[67] Serra, M.; Madau, P.; Chessa, M. F.; Caddeo, M.; Sanna, E.; Trapani, G.; Franco, M.; Liso, G.; Purdy, R. H.; Barbaccia, M. L.; Biggio, G. Br. J. Pharmacol., 1999, 127, 177-87.

[68] Chaki, S.; Funakoshi, T.; Yoshikawa, R.; Okuyama, S.; Okubo, T.; Nakazato, A.; Nagamine, M.; Tomisawa, K. Eur. J. Pharmacol., 1999, 371, 197-204.

[69] Okuyama, S.; Chaki, S.; Yoshikawa, R.; Ogawa, S.; Suzuki, Y.; Okubo, T.; Nakazato, A.; Nagamine, M.; Tomisawa, K. Life Sci., 1999, 64, 1455-64.

[70] Zhang, M.-R.; Maeda, J.; Furutsuka, K.; Yoshida, Y.; Ogawa, M.; Suhara, T.; Suzuki, K. Bioorg. Med. Chem. Lett., 2003, 13, 201204.

[71] Culty, M.; Silver, P.; Nakazato, A.; Gazouli, M.; Li, H.; Muramatsu, M.; Okuyama, S.; Papadopoulos, V. Drug Dev. Res., 2001, 52, 475-484.

[72] Bonoczk, P.; Gulyas, B.; Adam-Vizi, V.; Nemes, A.; Karpati, E.; Kiss, B.; Kapas, M.; Szantay, C.; Koncz, I.; Zelles, T.; Vas, A. Brain Res. Bull., 2000, 53, 245-54.

[73] Lorincz, C.; Szasz, K.; Kisfaludy, L. Arzneimittel-Forschung, 1976, 26, 1907.

[74] Molnar, P.; Erdo, S. L. Eur. J. Pharmacol., 1995, 273, 303-6.

[75] Hidaka, H.; Endo, T. Adv. Cyclic Nucleotide Protein Phosphorylation Res., 1984, 16, 245-59.

[76] Beavo, J. A. Physiol. Rev., 1995, 75, 725-48.

[77] Gulyas, B.; Halldin, C.; Vas, A.; Banati, R. B.; Shchukin, E.; Finnema, S.; Tarkainen, J.; Tihanyi, K.; Szilagyi, G.; Farde, L. J. Neurol. Sci., 2005, 229-230, 219-223. 